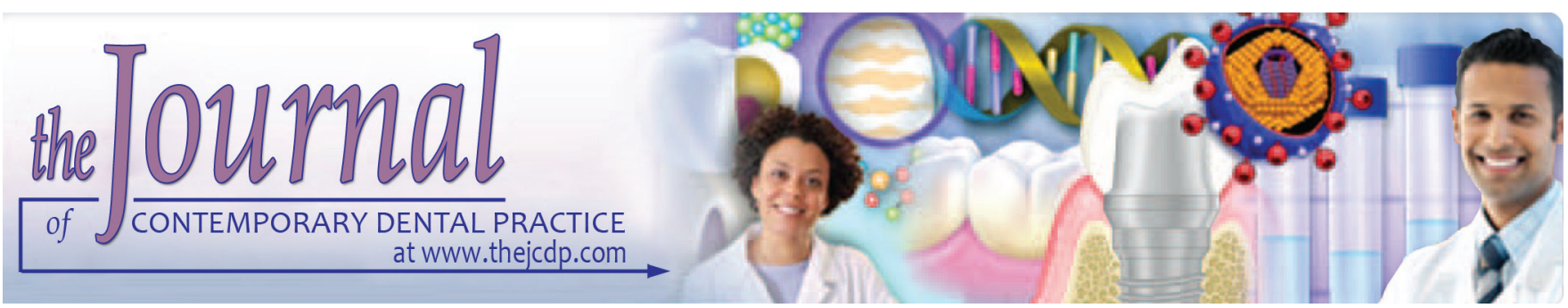

\title{
Comparative Evaluation of Cytotoxicity and Genotoxicity of Two Bioceramic Sealers on Fibroblast Cell Line: An in vitro Study
}

\author{
${ }^{1}$ Anoop V Nair, ${ }^{2}$ Moksha Nayak, ${ }^{3}$ L Krishna Prasada, ${ }^{4}$ Veena Shetty, ${ }^{5} \mathrm{CN}$ Vijay Kumar, ${ }^{6}$ Rakesh R Nair
}

\begin{abstract}
Aim: The purpose of this study was to evaluate and compare the cytotoxicity and genotoxicity of two bioceramic root canal sealers: EndoSequence BC and iRoot SP with zinc oxide eugenol sealers on fibroblast cell line.
\end{abstract}

Materials and methods: The sealers tested were zinc oxide eugenol, EndoSequence BC, and iRoot SP. Each material was mixed according to the manufacturer's instructions and mounted into sterile polyethylene color-coded rings, for cytotoxicity and genotoxicity evaluation.

After 48 hours, the set materials were transferred to previously marked wells and cytotoxicity evaluation to L929 murine fibroblast cells was done by 3-(4,5-dimethylthiazol-2-yl)-2, 5-diphenyltetrazolium bromide (MTT) assay. The percentages of viable cells were then calculated and values were statistically analyzed by Kruskal-Wallis test.

The evaluation of genotoxicity of the materials to L929 murine fibroblast cells was carried out by Comet assay. To quantify deoxyribonucleic acid (DNA) damage, the following comet parameters were evaluated in the assay using Comet scoring software: tail length, tail moment, and Olive moment. The values were statistically analyzed using Kruskal-Wallis test with a significance value set to $p<0.05$.

Results: The results of the study showed that both cytotoxicity and genotoxicity evaluation by MTT assay and Comet assay

\footnotetext{
${ }^{1}$ Kamala Dental Super Specialty Hospital, Thiruvananthapuram Kerala, India

2,3,6 Department of Conservative Dentistry and Endodontics, KVG Dental College and Hospital, Sullia, Karnataka, India

${ }^{4}$ Department of Microbiology, K.S. Hegde Medical Academy Nitte University, Mangaluru, Karnataka, India

${ }^{5}$ Department of Conservative Dentistry and Endodontics Subbaiah Institute of Dental Sciences, Shimoga, Karnataka, India

Corresponding Author: CN Vijay Kumar, Department of Conservative Dentistry and Endodontics, Subbaiah Institute of Dental Sciences, Shimoga, Karnataka, India, Phone: +919480047110, e-mail: drvijaycn@gmail.com
}

can be done on L929 murine fibroblast cell line. Among the three tested materials, zinc oxide eugenol showed maximum cytotoxicity to the cells $(30.64 \%$ viable cells), followed by EndoSequence BC (71.33\% viable cells) and iRoot SP $(75.11 \%$ viable cells). The evaluation of DNA damage by genotoxicity assessment showed iRoot SP to be least genotoxic followed closely by EndoSequence BC. Zinc oxide eugenol was genotoxic and induced more DNA damage on the fibroblast cell line studied. The statistical analyses for both the assays were nonsignificant.

Conclusion: All the three tested sealers showed varying degrees of cytotoxicity and genotoxicity while using fibroblast cell line. Zinc oxide eugenol was most toxic in both the assays and iRoot SP showed least toxicity, followed closely by EndoSequence BC.

Keywords: 3-(4,5-dimethylthiazol-2-yl)-2,5-diphenyltetrazolium bromide assay, Comet assay, Cytotoxicity, Endosequence BC, Fibroblasts, Genotoxicity, iRoot SP, L929, Zinc oxide eugenol.

How to cite this article: Nair AV, Nayak M, Prasada LK, Shetty V, Kumar CNV, Nair RR. Comparative Evaluation of Cytotoxicity and Genotoxicity of Two Bioceramic Sealers on Fibroblast Cell Line: An in vitro Study. J Contemp Dent Pract 2018;19(6):656-661.

Source of support: Nil

Conflict of interest: None

\section{INTRODUCTION}

Endodontic therapy aims at the elimination of residual pulp, tissue breakdown products, and microorganisms present inside the root canal system and followed by three-dimensional obturation. ${ }^{1}$ Any irritating material extruded beyond the apical foramen may cause inflammation, delaying or preventing the healing process. $^{2}$ Biocompatible materials stimulate the healing of the injured tissues, without causing any adverse effects. Bertram et al stated that cytotoxic materials can kill the 
cells in the periapex, while materials with genotoxic potential induce genome instability. ${ }^{3}$ Hence, evaluation of cytotoxicity and genotoxicity is of utmost importance.

Cytotoxicity and genotoxicity can be measured by a variety of methods. The MTT assay for cytotoxicity evaluation has the advantage of simplicity, speed, precision, and reproducibility. Comet assay or single-cell electrophoresis is a test for quantitative DNA damage assessment in mammalian cells. ${ }^{2,3}$

Permanent cell lines, e.g., HeLa, 3T3, or L929 cells and primary/diploid human cells, mainly oral fibroblasts, are used for these experiments. ${ }^{4}$ Fibroblasts are major cells of connective tissue, the predominant cell type of periodontal ligament and are the most important collagen producers in this tissue (McCulloch and Bordin, Kumada and Zhang). Moreover, they secrete matrix metalloproteinase, which is a key event for the progression of inflammatory process produce and protect the connective tissue. Studies with established cell lines are used because of the reproducibility of the results and they multiply rapidly with an unlimited life span. ${ }^{5}$

A number of sealers are available to be used along with gutta percha. Sealers with adhesive properties and new-age bioceramic sealers are the sealers of choice presently. Bioceramic sealers have several advantages over other root canal sealers which include enhanced biocompatibility, increased strength of the root following obturation, strong antibacterial property, nontoxic, bioinert, bioactive or biodegradable, easy to apply, and excellent sealing property. EndoSequence BC and iRoot SP and bioceramic root canal sealers are new additions to the endodontic sealers. ${ }^{6}$

Various studies have been done to assess the cytotoxicity of bioceramic sealers, however. The interactions of these materials with fibroblasts have not been fully understood. Hence, this study aims to compare and evaluate the biocompatibility of new-age bioceramic sealers on L929 fibroblast cell line.

\section{MATERIALS AND METHODS}

\section{MTT Assay and Comet Assay}

The present study was approved by the ethical committee of KVG Dental College and Hospital, Sullia, and the study was performed at NUCSER Institute, KSHEMA, Mangaluru, India.

\section{MTT Assay}

\section{Sample Preparation}

Standardized cell line, Murine lung fibroblasts L929 were used for the study. The cell line was procured from NUCSER Institute, Mangaluru, India.
The three root canal sealers used in the study, zinc oxide eugenol (Tubli-seal, SybronEndo), EndoSequence BC (Brasseler, USA), and iRoot SP (Veriodent, Vancouver, Canada) were mixed under aseptic conditions, according to the manufacturer's instructions. Zinc oxide eugenol was mixed in a powder-liquid ratio of 4:1 and placed in white sterile polyethylene rings. The second and third group, bioceramic sealers, EndoSequence BC, and iRoot SP, which were premixed, were then placed in yellow polyethylene rings represented. The specimens were allowed to set completely for 48 hours at $37^{\circ} \mathrm{C}$ and $100 \%$ humidity, under sterile conditions. After setting, the tubes were removed and the set material was transferred to previously marked tissue culture plates (Table 1).

Serial dilutions of cells in culture medium from $4 \times 10^{3}$ cells per $\mathrm{mL}$ were prepared and plated out, in triplicate, $100 \mu \mathrm{L}$ of the dilutions to wells of a microtiter plate and placed at $37^{\circ} \mathrm{C}, 5 \% \mathrm{CO}_{2}$ incubator for 2 days. The cells were then treated with the experimental materials in previously marked tissue culture plates.

Periodically, the cells were then viewed under an inverted microscope for the presence of intracellular punctate purple precipitate. When the purple precipitate became clearly visible under the microscope, $100 \mu \mathrm{L}$ of detergent reagent was added to all wells, including controls and swirled gently, but not shaken. Then the plates were left covered overnight at room temperature.

The following day, the plate covers were removed and the absorbance in each well, including the blanks, was measured at $570 \mathrm{~nm}$ in a microtiter plate reader (absorbances can be read with any filter in the wavelength range of 550-600 nm). The reference wavelength was higher than $650 \mathrm{~nm}$. The mean absorbances of the wells containing the various groups were then analyzed statistically and the percentage viability was then calculated using the formula:

$$
\text { Percentage of viable cells }=\frac{A}{B \times 100}
$$

where A-viable cells in the experimental well, B-viable cells in the control.

Cytotoxicity was then rated based on cell viability relative to controls as

- Not cytotoxic->90\% cell viability

- Slightly cytotoxic-60 to $90 \%$ cell viability

Table 1: Groups for comet assay

\begin{tabular}{lll}
\hline Group & Content & Coding on slides \\
\hline I & $\begin{array}{l}\text { Test cells treated with zinc oxide } \\
\text { eugenol }\end{array}$ & W1, W2 \\
II & $\begin{array}{l}\text { Test cells treated with } \\
\text { EndoSequence BC }\end{array}$ & Y1, Y2 \\
III & $\begin{array}{l}\text { Test cells treated with iRoot SP } \\
\text { IV }\end{array}$ & Y3, Y4 \\
\hline
\end{tabular}


- Moderately cytotoxic-30 to 59\% cell viability

- Strongly cytotoxic-<30\% cell viability (as explained by Dahl et al) ${ }^{7}$.

Results obtained were then charted on a spreadsheet.

\section{Comet Assay}

The cells treated with the test materials according to the groups were divided, labeled, and were first trypsinized in a vial, then centrifuged to get a pellet of cells. $30 \mu \mathrm{L}$ of the pellet was layered onto a slide with normal melting agarose and then a cover slip was placed. This agarose layer was sandwiched between a layer of $0.6 \%$ normal melting-point agarose and a top layer of $0.5 \%$ low melting-point agarose on fully frosted slides. It was then refrigerated so as to solidify the low melting agarose. After solidification of the agarose layer, slides were immersed in lysing solution for 2 hours, as lysing helps in the liberation of DNA (Table 2).

The slides were then gently removed from the lysing solution and placed side by side on the horizontal gel box near one end, sliding them as close together as possible. The buffer reservoirs were filled with freshly made electrophoresis buffer. The slides were immersed in the alkaline buffer for about 20 minutes to allow for unwinding of the DNA and the expression of alkalilabile damage.

The power supply was then turned off. The slides were gently removed from the buffer and placed on a drain tray. Each slide was then coated drop wise with neutralizing buffer and kept for 5 minutes. The slides were drained and the procedure was repeated two more times. This procedure was done to remove the alkalinity of the solution.

Now, the slides were stained with $80 \mu \mathrm{L}$ ethidium bromide and left for 5 minutes, then dipped in chilled distilled water to remove excess stain. The coverslip was then placed over it and the slides were scored immediately with a fluorescent microscope. About 20 to 50 cells/slide were scored, thereby scoring 50 to 100 cells per sample.

For visualization of DNA damage, observations were made of ethidium bromide-stained DNA using a 40x objective on the fluorescent damage.

For quantification of the data, Q Capture Pro 7 image

Table 2: Groups for MTT assay

\begin{tabular}{lll}
\hline Group & Content & $\begin{array}{l}\text { Coding on tissue } \\
\text { culture plates }\end{array}$ \\
\hline I & $\begin{array}{l}\text { Test cells treated with zinc oxide } \\
\text { eugenol }\end{array}$ & W1, W2, W3 \\
II & $\begin{array}{l}\text { Test cells treated with } \\
\text { EndoSequence BC }\end{array}$ & Y1, Y2, Y3 \\
III & Test cells treated with iRoot SP & Y4, Y5, Y6 \\
IV & Untreated control cells & C1, C2 \\
\hline
\end{tabular}

analysis software and Comet Score software (autocomet. com) were used linked to a CCD camera to assess the quantitative and qualitative extent of DNA damage in the cells by measuring the length of DNA migration and the percentage of migrated DNA. Finally, the program calculates the tail moment; 50 to 100 randomly selected cells were analyzed per sample.

\section{Tail Length}

Tail length is the distance of DNA migration from the body of the nuclear core and it is used to evaluate the extent of DNA damage. The tail length determines the length of DNA migration and is directly related to the DNA fragment size and the extent of DNA damage.

Tail length $=\frac{\text { Tail extent }(\text { Tail from center })+\text { Head extent }}{2}$

\section{Tail Moment}

It is defined as the product of the tail length and the fraction of total DNA in the tail.

$$
\begin{gathered}
M_{\text {Text }}=\mathrm{L} \times \frac{\mathrm{DNA}}{100} \\
\mathrm{~L}=\text { length of the tail or body } \\
\mathrm{DNA}=\mathrm{DNA} \text { of tail or body given as a percentage } \\
\mathrm{CG}=\text { center of gravity of the tail or body weighted by gray } \\
\text { values } \\
\mathrm{CG}_{\mathrm{H}}=\text { center of gravity of the head weighted by gray values } \\
\text { DNA }=\text { tail or body DNA }
\end{gathered}
$$

\section{RESULTS}

\section{MTT Assay for Cytotoxicity}

Absorbance values from the spectrophotometer were plotted on a spreadsheet and mean absorbance values were determined using Kruskal-Wallis test, with significance level set to $p<0.05$. No statistical significance was seen between the groups evaluated. Group II EndoSequence BC and group III iRoot SP showed similar absorbance values (0.347 and 0.367). Group I zinc oxide eugenol showed the least absorbance values (Fig. 1). The results proved that the bioceramic materials tested (groups II and III) were slightly cytotoxic when compared with group I, zinc oxide eugenol, which was moderately cytotoxic, when evaluated by criteria of Dahl et al. iRoot SP (group III) was the least cytotoxic among the three materials tested.

\section{Comet Assay for Genotoxicity}

No statistical significance was seen between the groups evaluated. Among the three parameters evaluated, group II EndoSequence BC and group III iRoot SP showed least genotoxicity in two parameters (Graph 1). Group I zinc 


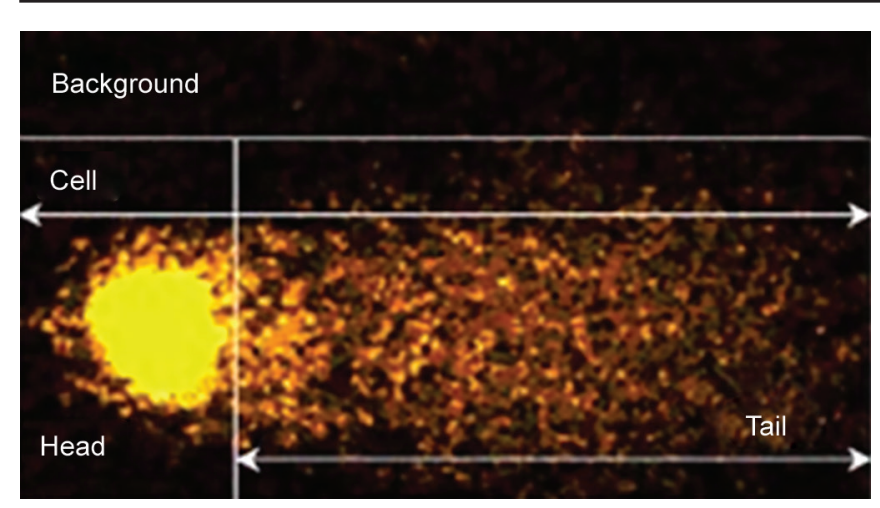

Fig. 1: Schematic representation of a comet

oxide eugenol showed highest genotoxicity. Bioceramic materials tested showed different levels of cytotoxicity and genotoxicity and in terms of biocompatibility, iRoot SP was most biocompatible (Graphs 2 and 3).

\section{DISCUSSION}

The fluid tight sealing of the root canal by means of a three-dimensional obturation of the pulp space constitutes the key factor for successful endodontic therapy. Root canal sealers are expected to be confined within the root canal but they may inadvertently extrude into the periradicular tissue and consequently cause tissue irritation and delayed healing. ${ }^{3}$ The biological properties of these materials are important as cytotoxic materials can damage periapical tissues, and materials with mutagenic potential can induce DNA mutations, possibly causing malignant transformation of the cells. ${ }^{2}$

EndoSequence BC and iRoot SP sealers are bioceramicbased sealers. They are composed of tricalcium silicate, dicalcium silicate, calcium phosphate, calcium hydroxide, zirconium oxide, and colloidal silica. Manufacturers claim that bioceramic sealers form hydroxyapatite during the

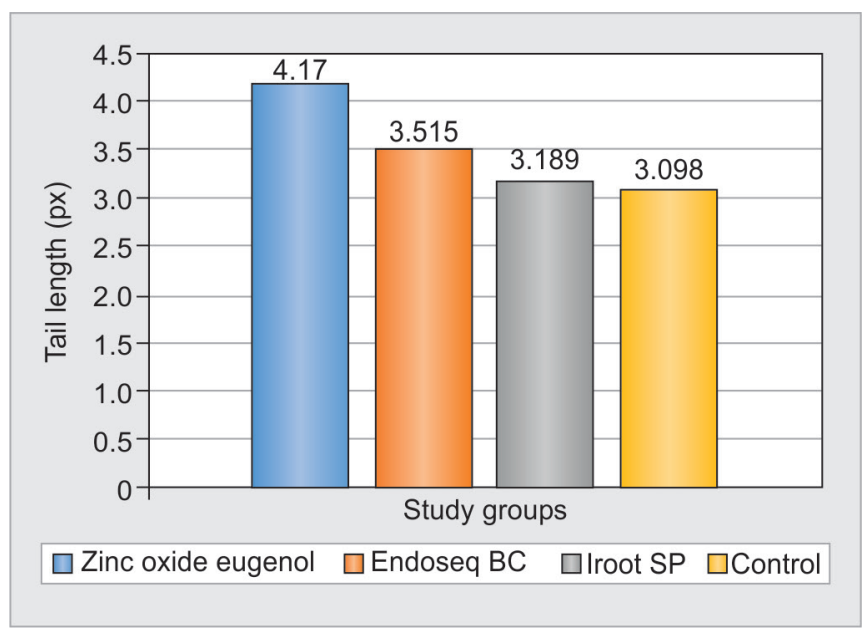

Graph 2: Graphical representation of comet assay parameter, tail length of fibroblasts exposed to the root canal sealers

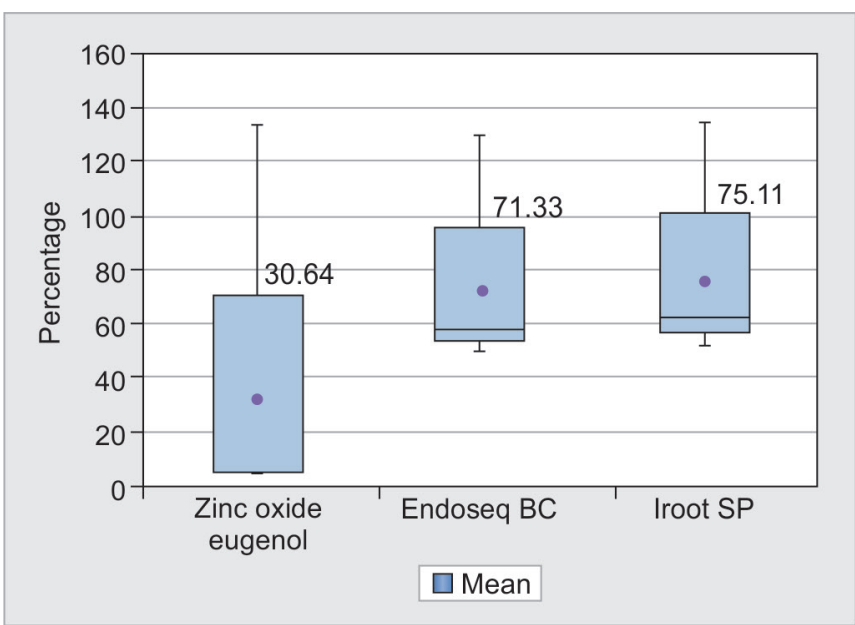

Graph 1: Graphical representation of cellular viability (cytotoxic effects) of tested materials relative to control (100\% viability)

setting process and ultimately create a chemical bond between dentinal wall and the sealer. These are convenient, premixed, ready-to-use injectable white hydraulic cement pastes developed for permanent root canal filling and sealing applications. It exhibits potent antimicrobial action, excellent biocompatibility, significant stimulation of periodontal regeneration, are osteoconductive, and do not shrink. They have very fine particle size of less than 2 microns, hence can be delivered with a 0.012 capillary tip. Its hydrophilicity, small particle size, and chemical bonding to the canal walls also contribute to its excellent hydraulics. ${ }^{8}$

The MTT assay is a standardized method that indicates the effect on cell viability, depending on the conversion of the water-soluble methylthiazol tetrazolium to an insoluble purple formazan in the mitochondria of living cells. This is then solubilized, and its concentration can then be determined spectrophotometrically by measuring at a certain wavelength (500-600 nm). The MTT cell

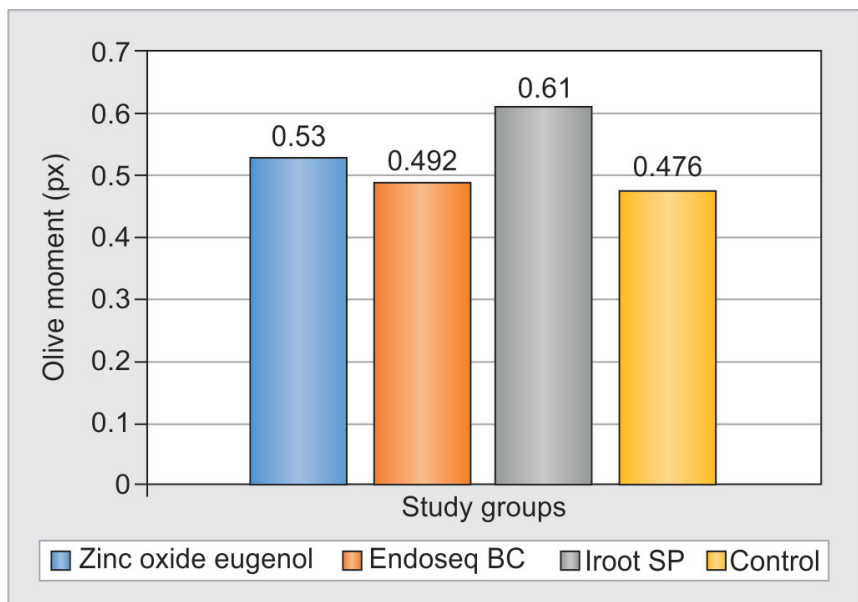

Graph 3: Graphical representation of comet assay parameter, olive moment of fibroblasts exposed to the root canal sealers 
proliferation assay measures the cell proliferation rate and conversely, when metabolic events lead to apoptosis or necrosis, the reduction in cell viability. An increase in cell number results in an increase in the amount of MTT formazan formed and an increase in absorbance. ${ }^{9}$

Studies done by Bin et al, ${ }^{1}$ Kangarloo et $\mathrm{al}^{5}{ }^{5}$ and Eldeniz using MTT assay for determining cytotoxicity of various root canal sealers on Chinese hamster fibroblasts (V79), human leukocytes, human gingival fibroblasts, and L929 murine fibroblast cells, have proven the success of this assay. ${ }^{1-5}$ The use of the MTT method does have limitations influenced by the physiological state of cells and variance in mitochondrial dehydrogenase activity in different cell types. Nevertheless, the MTT method of cell determination is useful in the measurement of cell growth in response to mitogens, antigenic stimuli, growth factors, and other cell growth-promoting reagents, cytotoxicity studies, and in the derivation of cell growth curves. ${ }^{10}$

Fibroblasts are the major cells of connective tissue and have the ability to produce and protect connective matrix. Although different cells are used for cytotoxic evaluation, one of the most common is rat L929 fibroblasts. The choice of this cell line for the study permits a lot of advantages, such as easy to prepare and culture without the individual difference of primary cells, accurate evaluation of the changes, excluding factors, such as age, metabolic and hormonal states of the donor, which might influence the cells in a primary culture. Hence, the cell line used in the present study is L929 mouse fibroblasts. ${ }^{5-10}$

The results of our studies are in agreement with studies done by Hensten-Petterson and Helgland who have shown that zinc oxide eugenol when applied to cells in culture is decidedly cytotoxic. Catanzaro and Persinoto $^{11}$ demonstrated a large influx of macrophages into the lesion with subcutaneous implantation of zinc oxide eugenol for both short and long periods. ${ }^{12}$ Ranade and $\mathrm{Kamra}^{4}$ compared the tissue toxicity level of zinc oxide eugenol with epoxy resin-based root canal sealers, gutta percha, and calcium hydroxide, and found that zinc oxide eugenol elicited the maximum inflammatory response amongst the four. ${ }^{1} \mathrm{Zmener}$ et al and Beagrie et al have reported that zinc oxide and eugenol are cytotoxic to several animal and human cell lines and connective tissues. However, it has been shown that, even though the toxicity of zinc oxide eugenol increased over the days, the sealer containing iodoform showed an increase in toxicity initially and then sharply decreased from the 7th to the 15 th day study period. ${ }^{2}$

Our results on cytotoxicity of bioceramic sealers are in agreement with the study done by Loushine et $\mathrm{al}^{13}$ who evaluated EndoSequence BC with AH Plus using MTT assay and found that EndoSequence BC remained moderately cytotoxic. Willershausen et $\mathrm{al}^{14}$ studied the cytotoxicity of EndoSequence BC on human periodontal ligament fibroblast cells using MTT assay and concluded that EndoSequence BC can be considered a biocompatible material, although no genotoxicity assessment was done in the study. Zoufan et $\mathrm{al}^{15}$ evaluated the cytotoxicity of EndoSequence BC with gutta flow by MTT assay on L929 cells, similar to the present study, and concluded that EndoSequence BC and gutta flow had lower cytotoxicity than the AH Plus and Tubli-seal sealers.

Bioceramic sealers are exceedingly biocompatible due to their osteoconductive properties, highly alkaline $\mathrm{pH}$ (12.9) which enhances its bactericidal properties and continued release of $\mathrm{Ca}$ ions. The calcium silicates in the powder hydrate to produce a calcium silicate hydrate gel and calcium hydroxide. The calcium hydroxide reacts with the phosphate ions to precipitate hydroxyapatite and water. The water continues to react with the calcium silicate to precipitate additional gel-like calcium silicate hydrate. The water supplied through this reaction is an important factor in controlling the hydration rate and the setting time. ${ }^{16}$

Rezende et $\mathrm{al}^{17}$ studied the genotoxicity of zinc oxide eugenol and concluded it to be considerably genotoxic. ${ }^{2-18}$ The presence of free eugenol in the sealer has been attributed as the cause of toxicity. Huang TH evaluated the genotoxicity of zinc oxide eugenol-based, calcium hydroxide-based, and epoxy resin-based sealers by comet assay, and stated that the zinc oxide eugenol-based sealers did not always cause a dose-dependent increase in genotoxicity and the highest amount of DNA damage was caused by resin-based sealers. ${ }^{2}$

In the present study, for the first time, both cytotoxicity and genotoxicity of EndoSequence BC and iRoot SP were individually evaluated and compared with zinc oxide eugenol. All the materials were tested after 48 hours and no evaluation was done after prolonged intervals of time, which would be a more accurate way of interpreting longterm biocompatibility. Although the first line of tests to assess biocompatibility are cytotoxicity and genotoxicity evaluation, secondary tests like sensitization, implantation, mucosal irritation tests, and further usage tests are necessary before the products can be considered biocompatible.

\section{CONCLUSION}

Investigating potential cytotoxic and genotoxic effects arising from dental materials, including root canal sealers, is a delicate task. It requires special caution during the preparation of materials and processing of data, without which both results and their clinical implications may be impaired. Within the limitations and parameters of the present study, it was concluded that MTT assay and comet assay proved successful in assessing the 
biocompatibility. All the tested materials were cytotoxic and genotoxic. Among the three materials tested, iRoot SP showed least cytotoxicity and genotoxicity to the cell line. EndoSequence BC and iRoot SP showed similar values in the cytotoxicity and genotoxicity assays. Zinc oxide eugenol was moderately cytotoxic and it was genotoxic to the cell line studied, when compared with the bioceramic sealers. In terms of biocompatibility, it could be concluded that the bioceramic sealers showed better biocompatibility than the traditionally used zinc oxide eugenol.

\section{REFERENCES}

1. Bin CV, Valera MC, CamargoSE, RabeloSB, Silva GO, Balducci I, Camargo $\mathrm{CH}$. Cytotoxicity and genotoxicity of root canal sealers based on mineral trioxide aggregate. J Endod 2012 Apr;38(4):495-500.

2. Miletic I, Jukic S, Anic I, Zeljezic D, Garaj-Vrhovac Osmak M. Examination of cytotoxicity and mutagenicity of AH26 and AH Plus sealers. Int Endod J 2003 May;36(5):330-335.

3. Baraba A, Zeljezic D, Kopjar N, Mladinic M, Anic I, Miletic I. Evaluation of cytotoxic and genotoxic effects of two resinbased root-canal sealers and their components on human leucocytes in vitro. Int Endod J 2011 Jul;44(7):652-661.

4. Ranade MP, Kamra AL. A comparative tissue toxicity evaluation of four endodontic materials. Endodontology 2003;15: 7-13.

5. Kangarloo A, Sattari M, Rabiee F, Dianat SO. Evaluation of cytotoxicity of different root canal sealers and their effect on cytokine production. Int Endod J 2009 Winter;4(1):31-34.

6. Bouillaguet S, Wataha JC, Tay FR, Brackett MG, Lockwood PE. Initial in vitro biological response to contemporary endodontic sealers. J Endod 2006 Oct;32(10):989-992.
7. Dahl JE, Frangou-Polyzois MJ, Polyzois GL. In vitro biocompatibility of denture relining materials. Gerodontology 2006 Mar;23(1):17-22.

8. Malhotra S, Hegde MN, Shetty C. Bioceramic technology in endodontics. Br J Med Med Res 2014 Apr;4(12):2446-2454.

9. Moharamzadeh K, Brook IM, Noort RV. Biocompatibility of resin based dental materials. Materials (Basel) 2009 Jun;2(2):514-548.

10. Key JE, Rahemtulla FG, Eleazer PD. Cytotoxicity of a new root canal filling material on human gingival fibroblasts. J Endod 2006 Aug;32(8):756-758.

11. Ho YC, Huang FM, Chang YC. Mechanisms of cytotoxicity of eugenol in human osteoblastic cells in vivo. Int Endod J 2006 May;39(5):389-393.

12. Camps J, About I. Cytotoxicity testing of endodontic sealers: a new method. J Endod 2003 Sep;29(9):583-586.

13. Loushine BA, Bryan TE, Looney SW, Gillen BM, Loushine RJ, Weller RN, Pashley DH, Tay FR. Setting properties and cytotoxicity evaluation of a premixed bioceramic root canal sealer. J Endod 2011 May;37(5):673-677.

14. Willershausen I, Callaway A, Briseno B, Willershausen B. In vitro analysis of the cytotoxicity and the antimicrobial effect of four endodontic sealers. Head Face Med 2011 Aug;7:15.

15. Zoufan K, Jiang J, Komabayashi T, Wang YH, Safavi KE, Zhu Q. Cytotoxicity evaluation of Gutta Flow and Endo Sequence BC sealers. Oral Surg Oral Med Oral Pathol Oral Radiol Endod 2011 Nov;112(5):657-661.

16. Zhou HM, Shen Y, Zheng W, Li L, Zheng YF, Haapasalo M. Physical properties of 5 root canal sealers. J Endod 2013 Oct;39(10):1281-1286.

17. Rezende EF, Costa MCM, Fonseca JC, Ribeiro AO. Evaluation of the genotoxicity of zinc oxide eugenol cement to Allium cepa L. Maringa 2013 Oct-Dec;35(4):563-569.

18. Moura CC, Oliveira NC, Borges CR, de Souza MA, Biffi JC. Cytotoxic response of two cell lines exposed in vitro to four endodontic sealers. Braz J Oral Sci 2012 Apr-Jun;11(2):135-140. 